\title{
TANTANGAN KEWIRAUSAHAAN DI ERA EKONOMI DIGITAL
}

\author{
Kasidi
}

Fakultas Keguruan dan Ilmu Pendidikan Universitas Ivet, Indonesia

DOI: https://doi.org/10.31331/ieee.v1i1.1223

\section{Info Articles}

Sejarah Artikel:

Disubmit 6 April 2020

Direvisi 15 April 2020

Disetujui 1 Mei 2020

Keywords: Challenge;

Entrepreneurship; Digital

Economic Era
Pertumbuhan ekonomi digital semakin hari semakin melejit. Keadaan ini tidak dapat dilepaskan dari perkembangan kemajuan teknologi iformasi dan komunikasi dengan menggunakan aplikasi serba canggih, yaitu menggunakan bantuan media internet. Tantangan bagi para wirausahawan mau tidak mau, suka tidak suka harus mengikuti dan menyelaraskan dengan lopatan-lompatan kemajuan di bidang digital termasuk di dalamnya transaksi digital.

\section{Abstract}

Digital economic growth is increasing quickly. This situation can not be separated from the development of information and communication of advance technology by using sophisticated applications, namely using internet media. The challenge for entrepreneurs, want it or not, like it or not should follow and harmonize with the leaps of progress in the digital field including digital transactions 


\section{PENDAHULUAN}

Indonesia oleh dunia dipandang sebagai wilayah strategis, wilayah tumbuh dan berkembangnya ekonomi digital. Tamasek melaporkan bahwa ekonomi digital di Idonesia tahun 2019 mencetak US\$ 40 milyar atau setara dengan Rp.556,60 trilyun (www.liputan 6.com). Pertumbuhan ekonomi digital Indonesia merupakan yang tertinggi di kawasan Asia Tenggara. Pertumbuhan ekonomi digital di Negara-negara tetangga seperti: Thailand US\$ 16 milyar; Singapura US\$ 12 milyar; Vietnam US\$ 12 milyar; Malaysia US\$ 11milyar; dan Filipina US\$ 7 milyar.

Ekonomi digital dicirikan dengan semakin berkembangnya bisnis atau transaksi dagang yang menggunakan internet sebagai media dalam berkomunikasi, berkolaborasi dan kerjasama baik antar perusahaan maupun antar individu dalam rangka memasarkan suatu produk tertentu. Online shop atau toko online adalah suatu toko yang mempresentasikan suatu produk atau jasa melalui media internet (Makmur, 2018:3).Penelitian tentang faktor-faktor yang mempengaruhi minat wirausaha menunjukkan bahwa variabel minat wirausaha dipengaruhi sebesar $60,40 \%$ secara total oleh modal, skills, tempat, dan jiwa kewirausahaan (Mulyaningsih, 2012). Penelitian tentang sikap, motivasi, dan minat berwirausaha mahasiswa, memberikan kesimpulan bahwa variabel sikap dan motivasi tidak berpengaruh signifikan terhadap minat berwirausaha (Rosmiati, dkk, 2015). Entrepreneurship education has a significant infac on perceived desirability, perceived feasibility and perceived propencity to act(Purwana, dkk, 2018). Artinya, pendidikan kewirausaahaan berdampak signifikan terhadap rasa ingin, kecenderungan untuk melakukannya dan mewujudkannya.

Mata Kuliah Kewirausaahaan berpengaruh terhadap minat berwirausaha (Kuncoro, Rusdianto, 2016). Entrepreneurial knowledge, self-effiacy, and family factor have a significant impact on studen's entrepreneur intention respectively (Hutasuhut, Saidun 2018). Responden mempunyai hasrat keusahwanan yang tinggi, mana kala tanggapan keinginan dan tingkah laku proaktif mempunyai hubungan yang positif dengan hasrat keusahwanan (Alhaj, dkk, 2011). Terlepas dari pertentangan hasil penelitian yang dilakukan yang penulis contohkan tersebut, wirausaha harus dibangun dan dikembangkan serta perlunya mendapatkan pembinaan dari instansi-instansi terkait dalam rangka untuk memenangkan persaingan di era ekonomi digital.

Tapscot (1998) pertama kali memperkenalkan konsep digital ekonomi ini yang merupakan sebuah sosiopolitik dan sistem ekonomi yang mempunyai karakteristik sebagai ruang intelejen yeng meliputi: informasi, akses instrument informasi, pemrosesan informasi dan kapasitas komunikasi. Identifikasi komponen ekonomi digital meliputi idustri TIK, e-commerce, distribusi digital, penjualan produk melalui internet. Bagaimana wirausahawan menghadapi era ekonomi digital?

\section{PEMBAHASAN}

\section{Wirausaha di Era Digital}

Kegiatan wirausaha sebenarnya sudah ada semenjak abad 18, yaitu semenjak ditemukannya alat mesin bertenaga uap oleh seorang bernama James Watt. Tujuan utama kegiatan wirausaha pada saat itu bukan semata-mata mencari keuntungan, tetapi lebih ditekankan pada pertumbuhan dan perluasan sebuah organisasi. Ada dua belas karakteristik penting yang diperkenalkandalam ekonomi digital yang harus dipahami oleh para wirausahawan. Duabelas karakteristik tersebut adalah: (1) knowledge; (2) digitazion; (3) virtualization; (4) molecularization; (5) internetworking; (6) disintermediation; (7) convergence; (8) innovation; (9) presumption; (10) immediacy; (11) globalization; (12) discordance. (Tapscott,1998) 


\section{Knowledge}

Dalam era ekonomi digital, tanah, gedung, buruh, modal bukan lagi merupakan faktor produksi yang menetukan keberhasilan suatu bisnis, tetapi faktor pengetahuan (knowledge) sebagai faktor produksi utama yang akan menetukan sukses tidaknya suatu bisnis. Pengetahuan merupakan bangunan atribut yang melekat di dalam otak manusia. Oleh karena itu faktor intelegensi dari suber daya manusia merupakan penentu berhasil tidaknya dalam membangun suatu usaha. Agar pengetahuan memiliki manfaat yang tinggi, maka perlu elaborasi dengan pihak-pihak lain dalam bentuk kerjasama. Kecerdasan buatan (artificial intelegence) telah banyak mampu menggantikan pekerjaan manusia dalam menghasilkan produk berupa barang maupun jasa. Kecerdasan berupa perangkat keras maupun perangkat lunak dapat dijadikan alat penunjang dalam pengambilan keputusan. Konsep produksi ilmu pengetahuan dewasa ini akan menjadi kunci keberhasilan sebuah wirausaha atau bisnis. Keberhasilan wirausaha tidak lepas dari pengaruh internal seperti motivasi, perilaku, orientasi kerja, kreativitas, dan inovasi, sementara faktor dari luar yang turut berpengaruh terhadap kewirausahaan adalah keluarga, masyarakat, pendidikan, dan teknologi (Ulfah M, 2019). Masih berkaitan dengan wirausaha, bahwa intensi terbukti sebagai prediktor terbaik dalam menggambarkan perilaku di masa yang akan datang (Ajzen, 1991) berkaitan dengan bisnis di dunia maya. Tingkat pendidikan berpengaruh positif terhadap: (1) intepreneurial intention; (2) professional attraction entrepreneurial; (3) networking support entrepreneurial (Sandroto CW, dkk, 2018).

\section{Digization}

Proses transpormasi informasi menjadi digit format " 0 " dan " 1 " (bilangan berbasis dua) dikenal dengan istilah digitization. Proses tersebut keberadaannya telah mampu membuat suatu terobosan dan perubahan besar dalam dunia bisnis. Dapat kita saksikan saat ini bentuk gambar dua dimensi seperti lukisan dan foto telah dapat direpresentasikan ke dalam format kumpulan bit sehingga dengan mudah dapat disimpan dan dipertukarkan dengan menggunakan media elektronik. Dengan cara seperti itu mampu meningkatkan efisiensi kerja serta menurunkan biaya-biaya yang cukup signifikan berkaitan dengan biaya proses produksi, biaya penyimpanan dan pertukaran antar media. Perkembangan teknologi elektronika terakhir telah mampu mengkonversi format analog video dan audio ke dalam format digital. Pertukaran informasi yang serba cepat melalui internet dengan bantuan media elektronika ke seluruh penjuru dunia akan semakin mempermudah roses pengiriman dan pertukaran seluruh jenis informasi dengan cara digitalisasi. Produk dan jasa yang ditawarkan dapat direpresentasikan ke dalam bentuk digital sehingga dengan mudah dan murah ditawarkan ke pasar di seluruh dunia. Bias kita saksikan produk-produk dan jasa seperti: electronic publishing, virtual book store, internet banking, telemedicine, adalah produk-produk dan jasa yang dengan mudah ditawarkan melalui media internet.

\section{Virtualization}

Di era digital bisnis atau usaha dapat dijalankan dengan menggunaan perangkat sederhana seperti hand phone atau gatged dengan mengunduh aplikasi tertentu. Berbeda dengan model bisnis konvensional, dimana bisnis dilakukan dengan perangkat fisik yang nyata, seperti: gedung, alat produksi dan lain sebagainya. Bisnis melalui dunia maya hal seperti itu sudah sangat sedikit sekali dibutuhkan. Bisnis melalui dunia maya dikenal adanya istilah virtualisasi yang memungkinkan seseorang untuk memulai usahanya dengan perangkat sederrhana yang dapat menjangkau konsumen maupun calon konsumen ke seluruh dunia. Di dunia maya pelanggan cukup berhadapan dengan situs internet sebagai perusahaan (business to consumer). Demikian juga relasi antar pengusaha yang mengingikan untuk melakukan kerjasama. Dalam menjalin kerjasama proses yang terjadi lebih pada transaksi adalah pertukaran informasi secara virtual tanpa diperlukan kehadiran fisik antar pihak yang melakukan kerjasama. Bisnis dapat 
dilakukan selama 24 jam sehari secara on-line dan real time.Pertumbuhan pengguna pengguna $e$ commerce di Indonesia semakin hari semakain meningkat, seiring meningkatnya penggunaan internet di Indonesia. Menkominfo menyebutkan bahwa nilai transaksi e-commerce di Indonesia tahun 2013 mencapai angka Rp.130 triyun (Sarwandi 2017: 13)

\section{Molecularization}

Usaha yang mampu berkembang dan bertahan di era ekonomi digital hanya jika usaha itu mampu menerapkan bentuk molekul. Apa itu konsep usaha bentuk molekul tidak lain adalah suatu sistem yang flexible, mampu beradaptasi dan menyesuaikan diri setiap terjadinya perubahan yang terjadi yang kadang-kadang sulit untuk diprediksi. Bagi perusahaan, organisasi yang dikelola dengan menggunakan konsep struktur herarkis atau metrik sangat rentan dalam menghadapi perubahan lingkungan bisnis yang terus terjadi, sehingga akan memperlambat gerak usaha yang akan mempersempit, bahkan bisa menghilangkan pangsa pasarnya. Bisnis melalui dunia maya artinya berhadapan head to head dengan pelaku usaha di seluruh penjuru dunia. Struktur pasar maupun industri akan sangat dipengaruhi perilaku mereka yang merupakan manifestasi dari persaingan bebas. Bentuk strategi memenangkan persaingan dengan tujuan menguasai pasar yang lebih luas, sehingga efisiensi dan efektifitas mampu untuk dicapai.

\section{Internetworking}

Agar bisnis melalui dunia maya dapat membuahkan hasil sesuai dengan yang diharapkan, maka jalinan kerjasama dengan pihak-pihak terkait harus direncanakan dan dilakukan melalui suatu ikatan kerjasama yang terstruktur. Core bisnis harus ditentukan dan jalinan kerjasama dengan institusi lain harus dilakukan guna membantu pelaksanaan proses-proses penunjang, semisal jalinan kerjasama dengan vendor teknologi, content partners, merchant pemasok dan sebagainya. Berbisnis yang memiliki konsep ingin menguasai sumber daya sendiri dari hulu sampai hilir dipastikan tidak akan mampu bertahan lama dalam menghadapi pasar era digital.

\section{Disintermadiation}

Dalam berbisnis di era ekonomi digital mediator (broker) yang merupakan perantara terjadinya transaksi antara pemasok dengan pelanggan semakin tidak diperlukan. Bisnis dengan menggunakan media internet sudah tidak lagi membutuhkan mediator seperti: wholesaler, retailers, broadcasters, record companies dan sebagainya. Bisnis yang masih menggantungkan pemasarannya melalui media klasik akan tergilas oleh bisnis yang menggunakan media internet. Transaksi melalui media internet dapat terjadi sepanjang hari di mana saja tanpa dibutuhkan kehadiran secara fisik pihak-pihak yang terlibat.

\section{Convergence}

Sukses dalam berbisnis di dunia maya jika pelaku bisnis mampu mengintegrasikan (convergence) tiga hal, yaitu: computing, communications, dan content. Komputer merupakan syaraf pengolahan data dan informasi yang sangat dibutuhkan dalam melakukan transaksi usaha, sedangkan produk industri komunikasi yang paling dibutuhkan adalah infrastruktur teknologi informasi dan komunikasi (TIK) sebagai sarana penyalur data dan informsi ke seluruh penjuru dunia. Kompetisi yang sesungguhnya terletak pada industri isi (content) sebagai jenis pelayanan atau jasa yang ditawarkan kepada pasar lewat dunia maya. Tiga " $\mathrm{C}$ " tersebut merupakan syarat yang tidak bisa ditawar-tawar lagi untuk dikuasai dan di aplikasikan untuk meraih sukses usaha di era ekonomi digital.

\section{Innovation}

Bisnis di dunia nyata (konvensional) hanya mengenal waktu kurang lebih delapan jam dalam sehari semalam. Berbeda dengan berbisnis di dunia maya dengan menggunakan media internet, 
waktu berbisnis yang dapat dimanfaatkan pelaku bisnis adalah 24 (dua puluh empat jam) dalam sehari. Kondisi yang demikian akan sangat sulit dalam usaha untuk mempertahankan competitive advantage, karena apa yang dilakukan seseorang atau perusahaan internet lain dengan mudah ditiru pihak-pihak lain. Oleh karena itu kecepatan inovasi yang terus menerus sangat dibutuhkan untuk menjadi leader pasar. Cara baru harus terus diusahakan dan ditemukan untuk menyempurnakan bankan mengganti cara-cara yang selama ini dipakai agar dapat menjadi pemain kunci. Learning organizations concept dapat dipertimbangkan sebagai rujukan dalam menjalankan bisnis di dunia maya.

\section{Prosumption}

Di era ekonomi digital sulit untuk membedakan mana produsen mana konsumen, karena hampir semua konsumen teknologi informasi dengan mudah berubah menjadi produsen dan siap menawarkan produk dan jasa kepada masyarakat maupun komunitasnya. Jika seseorang harus membayar US $\$ 10$ dolar untuk mendapatkan akses ke dalam sebuah sistem, kemudian yang bersangkutan membentuk komunitas dan meminta anggota komunitas membayar jumlah tertentu kepadanya. Dengan cara demikian yang bersangkutan telah memperoleh pendapatan dari cara usaha yang cukup sederhana itu. Individu yang bersangkutan dikategorikan sebagai prosumer.

\section{Immediacy}

Bisnis di dunia maya pelanggan akan dihadapkan pada berbagai penyedia produk maupun jasa yang serupa bahkan sama. Pelanggan biasanya melakukan transaksi dengan pihak yang menawarkan produk dan jasa secara cheaper, better, dan faster. Cheaper adalah penentuan harga produk dan jasa yang paling murah dengan kualitas yang tinggi (better). Hal ini dapat dilakukan karena ongkos produksi, ongkos promosi bisa ditekan serendah-rendahnya dengan memanfaatkan teknologi informasi dan komunikasi melalalui media internet. Sedangkan faster merupakan layanan hantaran yang cepat dan tepat waktu di bandingkan dengan produk-produk dan jasa sejenis lainnya. Konsumen akan selalu memilih layanan yang dapat memberikan manfaat tertinggi, namun dengan cara yang mudah dan ongkos yang murah. Oleh sebab itu pelaku bisnis harus selalu peka terhadap kebutuhan pelanggan yang memerlukan kepuasan pelayanan dengan metode terpilih.

\section{Glbalization}

Bisnis di dunia maya sudah tidak mengenal batas ruang dan waktu. Pengetahuan (knowledge) merupakan sumber daya utama dalam menjalankan usaha, tidak dikenal apa yang dinamakan batas secara geografi, sehingga keberadaan entitas Negara menjadi kurang relevan dalam menjalankan bisnis di dunia maya. Pelaku bisnis akan melakukan bisnis dari tempat yang murah dan nyaman, menjual produk dan jasanya kepada konsumen, dan hasil penjualan itu akan ditransfer dan disimpan di Bank dengan mendapatkan bunga simpanan. Redefinisi segmentasi pasar yang selama ini dilakukan berdasarkan waktu dan ruang perlu untuk segera dilakukan karena masyarakat dunia ini telah menjadi satu kesatuan dalam wadah dunia maya, baik itu komunitas produsen maupun komunitas konsumen. Berjualan lewat dunuia maya dapat menggunakan media sosial seperti, face book, instagram, online mall. Hal-hal yang perlu memdapat perhatian dalam memajang produk berjualan di media sosial: (1) produk harus diberi kode untuk memudahkan merujuk barang; (2) image harus jelas dan informatif; (3) ukuran, warna, dan atribut lain harus disertakan sebagai standar menyajikan informasi produk; (4) keterangan yang mendukung inormasi produk, missal dasi slim fit, jadi tidak hanya sekedar dasi; (5) buat kategorisasi produk untuk mempermudah memilih produk (Feri Sulianta, 2015:49) 


\section{Discordance}

Fenomena perubahan budaya dan struktur sosial sebagai dampak konsekuensi logis perubahan sejumlah paradigma terkait dengan kehidupan sehari-hari. Perubahan yang pesat dalam dunia teknologi informasi turut membawa perubahan yang besar pada bidang-bidang yang diimplementasikan termasuk dunia bisnis (Madcom 2011: 1). Pertentangan terjadi karena perubahan motode kerja. Pekerjaan-pekerjaan yang dahulunya dikerjakan oleh tenaga manusia, secara masif digantikan oleh alat atau aplikasi tertentu, sehingga pengangguran tenaga kerja manusia semakin hari akan semakin bertambah. Pengangguran akan terjadi di segala sektor akibat semakin ringkasnya struktur organisasi. Mata pencaharian brokerakan hilang, para pekerja akhirnya menjadi workholic karena persaingan yang sangat ketat, pengaruh budaya mancanegara dengan sangat mudah diakses melalui media internet. Semua itu merupakan ciri dari era ekonomi digital. Ketidaksiapan suatu organisasi maupun individu dalam menghadapi tantangan perubahan yang sangat cepat dan masif dapat berakibat buruk terhadap usaha yang dijalankan.

\section{Cocreation}

Disamping dua belas karakteristik tersebut di atas yang harus dikuasai pelaku bisnis satu lagi karakteristik yang kiranya mampu meningkatkan daya saing adalah cocreation. Kolaborasi saja tidaklah cukup untuk menghadapi tantangan perubahan yang menghentak, namun harus diusahakan berlanjut menjadi kokreasi. Produk-produk dan jasa yang sudah dihasilkan melalui kolaborasi perlu dimodifikasi dengan melakukan kokreasi sehingga mampu memunculkan produk baru terbarukan baik dari segi bentuk, warna, kualitas, hantaran, ketepatan. Sebagai contoh kolaborasi jasa transportasi dengan jasa yang lain memunculkan kokreasi jasa: gojek, gofood, gosend, gotik, goclean dan kedepan barangkali akan terus bermunculan jasa go yang lainnya. Perusahaan-perusahaan yang semula sudah mapan dan memimpin pasar bahkan perusahaan monopoli sekalipun sudah mulai berbenah untuk melakukan kolaborasi, komunikasi dan kokreasi agar tetap eksis menghadapi persaingan yang terus berubah. Bisnis yang ingin menang sendiri semakin lama akan semakin tenggelam dalam persaingan jika tidak mau melakukan kolaborasi, komunikasi, dan kokreasi. Keuntungan berbisnis melalui dunia maya semestinya menekankan keuntungan untuk kesejahteraan masyarakat secara luas dan bukan menekankan keuntungan untuk individu atau kelompok. Kolaborasi, komunikasi dan kokreasi dapat menciptakan lapangan kerja baru, pengangangguran dapat terserap dan pendapatan masyarakat dapat terangkat. Pelaku bisnis sudah saatnya saling bergandengan tangan untuk menjalin kerjasama, tidak basa lagi memiliki anggapan dirinya yang paling berhasil untuk menghadapi persaingan usaha di dunia digital.

Kolaborasi yang dapat berlanjut ke kokreasi membutuhkan pola pemikiran yang kreatif dan inovatif. Disini sumber daya yang berupa ilmu pengetahuan (knowledge) merupakan sumber daya yang utama. Membangun kultur kolaboratif menjadi tantangan yang perlu dipecahkan bagi pelaku usaha, sebab hal ini tidak mudah untuk dilakukan antar pelaku usaha. Pelaku usaha yang sudah mapan biasanya masih terbiasa mempertahankan cara-cara konvensional yang selama ini mereka pakai dan menganggap posisi mereka lebih unggul dibandingkan pesaing lainnya. Kondisi ini sebenarnya akan dipatahkan oleh waktu. Kolaborasi dalam kontek pasar di era digital dicirikan oleh: mitra yang lebih muda, lebih dinamis, lebih segar, dan cara berbisnis yang berbeda (Kompas 12 Nopember 2019). Sikap inovatif, proaktif, berani menanggung risiko, otonomi, dan agresif bersaing (Layoo N, Rahman W, 2017) perlu dimiliki wirausahawan.

Ide-ide kreatif yang segar untuk terwujudnya kreasi perlu digali dan dikembangkan dengan cara melakukan kerjasama dengan orang-orang kreatif yang dilandasi oleh budaya kerja yang menyenangkan, tidak kaku, tidak birokratis apalagi otoriter. Perkembangan teknologi informasi dan komunikasi yang tiada batasnya perlu diimbangi flexibilitas cara dalam melakukan bisnis di 
era digital. Dengan cara yang seperti itu, maka akan diperoleh bisnis yang saling menguntungkan.

\section{SIMPULAN}

Era ekonomi digital ditandai semakin banyak dan maraknya transaksi bisnis yang dilakukan melalui internet. Produsen maupun konsumen membaur di dalam suatu ruang maya yang disebut dengan internet. Untuk dapat bersaing di dunia maya yang saling menguntungkan maka pelaku bisnis perlu menguasai dan memahami tiga belas karakteristik dalam berbisnis di era digital, yaitu: knowledge, digitalization, virtualization, melecularization, internetworking, disintermediation, convergence, innovation, immediacy, globalization, discordance, dan cocreation.

\section{DAFTAR PUSTAKA}

Ajzen I. (1991). The Theory of Planned Behavior Organizational Behavior and Human Decision Prosesses, USA: Academic Press, Inc

Alhaj KB,Yusof ZM, Edama N.(2011). Entrepreeneurial Intention: An Empirical Study of Community College Student in Malaysia. Jurnal Personalia Pelajar, Bil 14: 45-58

Hutasuhut \& Saidun. (2018). The Roles of Entrepreneurship Knowledge, Self-Efficy, Family, Education, and Gender on Entrepreneuriel Intention. Dinamika Pendidikan, 13(1), 90-105.

Kuncoro, A \& Rusdianto H. (2016). The Influence Of Entrepreneurship Subject On Students' Interest In Entrepreneurship With Hidden Curriculum as the Intervening Variable. Economics Education Studies Journal Vol 11 (1) 2016, 58-66

Layoo N \& Rahman W. (2017). Pengaruh Orientasi Kewirausahaan Dengan Kinerja Usaha Mikro Kecil di Kabupaten Banggai. Jurnal Ekonomi Pendidikan dan Kewirausahaan Vol.7, No.1, 2017, 29-44.

Madcom. (2011).Sukses Membangun Toko Online Dengan E-Commerce, Yogyakarta: Andi

Makmur R. (2018).Bisnis Online, Bandung: Informatika

Mulyaningsih. (2012). Faktor-Faktor yang Mempengaruhi Minat Wirausaha Pengelolaan Pangan Organik. Malang: Jurnal Wacana.

Purwana D, Suhud U, Wibowo SF. (2018). Determinant Factors of Studen' Entrepreneurial Intention: A Comparative Study. Dinamika Pendidikan, 13(1), 1-13

Rosmiati, Junias DTS, Munawar. (2015). Sikap, Motivasi, dan Minat Berwirausaha Mahasiswa. Jurnal Manajemen dan Kewirausahaan Vol.17, No.1, Maret 2015, 21-30.

Sandroto CW, Rahmawati W, Darmoyo S. (2018). The Role of Competencies and Education in Increasing Entrepreneurial Intention in Creative Economy. International Research Journal of Business Studies Vol. 11 No.1.

Sarwandi. (2017).Otodidak Bikin Toko Online Dengan Prestashop, Yogyakarta: MediaKom.

Suliana F. (2015), Berjualan dan Berpromosi Online Terbaik, Yogyakarta: Andi

Tapscott D, (1998). Growing up Digital The Rise of the Nex Generation, New York: McGraw Hill.

Ulfah M, (2019). Intensi Berwirausaha Mahasiswa di Kota Pekanbaru. Jurnal Daya Saing Vol. 5, No.3, Oktober 2019 